\title{
Evaluation of a Patient CAM-with-Chemotherapy Educational Brochure
}

\author{
Peter J. Smith, ${ }^{1,2}$ Alexandra M. Clavarino, ${ }^{1}$ Jeremy E. Long, ${ }^{2}$ and Kathryn J. Steadman ${ }^{1}$ \\ ${ }^{1}$ School of Pharmacy, The University of Queensland, Brisbane, QLD 4072, Australia \\ ${ }^{2}$ Sunshine Coast Cancer Care Services, Nambour General Hospital, Nambour, QLD 4560, Australia
}

Correspondence should be addressed to Peter J. Smith; peter.smith@health.qld.gov.au

Received 27 November 2014; Accepted 12 February 2015

Academic Editor: Karin Kraft

Copyright (c) 2015 Peter J. Smith et al. This is an open access article distributed under the Creative Commons Attribution License, which permits unrestricted use, distribution, and reproduction in any medium, provided the original work is properly cited.

Biologically active CAM may detrimentally interfere with chemotherapy treatment, so cancer patients require targeted, evidencebased information on chemotherapy-CAM integration consequences. The object of this study was to investigate the potential for medical doctor recommendation and patient acceptance of a purpose-designed patient educational brochure on the safe use of CAM with chemotherapy. Cancer care doctors $(n=17)$ were provided a draft version of a patient educational brochure developed by the authors and completed a structured feedback form. Cancer patients receiving treatment $(n=12)$ were provided with the brochure and completed the local health service consumer testing feedback form. All 17 doctors perceived a need for the brochure and all would recommend the brochure to their patients. Approximately $59 \%$ of the doctors indicated they would recommend the brochure to all patients receiving chemotherapy and $41 \%$ preferred that only patients using CAM or who enquired about CAM be given the brochure. Cancer patients receiving chemotherapy reported that the brochure information answered their questions and was easy to understand. This evidence-based CAM-chemotherapy patient brochure may be a useful adjunct for use by cancer care health professionals to educate patients on the potential dangers of biologically active CAM use with chemotherapy and to provide patients with safe CAM alternatives.

\section{Introduction}

The majority of patients receiving chemotherapy will consider taking complementary and alternative medicine (CAM) [1] at some time during their treatment. CAM is defined as a broad and diverse group of treatments and products that do not tend to be widely used by conventional healthcare professions [2]. Biologically active CAM have the potential to interact with conventional medicines, including antineoplastic treatments [3] and herbal CAM interactions with chemotherapy have been estimated to be responsible for a substantial number of unexpected toxicities and possible undertreatment of some cancers [4]. Studies on patients receiving chemotherapy have concluded that one-quarter of patients taking biologically active herbal and/or vitamin supplemental CAM are at risk of a clinically relevant interaction $[5,6]$.

Mind-body CAM has shown efficacy in supportive care for patients receiving chemotherapy and when applied by appropriately trained therapists, using reasonable patient specific precautions, it is safe to use at that time [7]. Mindbody therapy CAM is a safe option for cancer patients who wish to use CAM during chemotherapy.

Patients would like to receive specific information on which CAM is safe to use with chemotherapy before their treatment commences [6]. The purpose of this study was to evaluate the acceptance by doctors and consumers of an evidence-based brochure designed to provide answers to common questions chemotherapy patients have about CAM use with chemotherapy.

\section{Methods}

An educational brochure was developed by the authors (see Appendix in Supplementary Material available online at http://dx.doi.org/10.1155/2015/408430) with the aim of providing a tool for use by cancer care doctors and associated cancer health professionals to give evidence-based guidance 
TABLE 1: Demographic characteristics of the chemotherapy patients surveyed $(n=12)$.

\begin{tabular}{ll}
\hline Characteristics & $n$ \\
\hline Age, years & 1 \\
$31-40$ & 4 \\
$41-50$ & 2 \\
$51-60$ & 5 \\
$61-70$ & \\
Sex & 7 \\
Female & 5 \\
Male & \\
Highest level of education & 1 \\
Left school before year 10 & 4 \\
Secondary (year 10) & 3 \\
Secondary (year 12) & 4 \\
Tertiary & \\
\hline
\end{tabular}

to patients on CAM use with chemotherapy. Eighteen doctors at the Sunshine Coast Cancer Care Service (Nambour Hospital, Queensland, Australia) were asked to provide feedback concerning the draft patient brochure through completing a structured feedback form. One doctor did not return the feedback form. Six oncologists, 2 oncology training registrars, 5 haematologists, 2 haematology training registrars, and 2 general rotational hospital registrars gave written feedback. Following doctor feedback, the draft brochure was submitted to the local health service publishing unit for publication. The relevance, clarity, presentation, readability, and acceptance of the brochure were tested through distribution to 12 chemotherapy patients (Table 1) who each completed the Sunshine Coast Hospital and Health Service consumer testing feedback form.

\section{Results}

3.1. Doctor Feedback. All 17 doctors thought there was a need for the brochure and responded that they would recommend the brochure to their patients (Table 2 ). Approximately 59\% of doctors said they would recommend the brochure to all patients receiving chemotherapy, but $41 \%$ preferred that only patients using CAM or asking about CAM be given the brochure. Two doctors preferred to personally give the educational CAM brochure to the patient, 7 at nurse education clinic, 3 by the doctor or at nurse clinic, and 5 by doctor, nurse clinic, or other cancer care health professional. No doctors sought to limit the brochure to early stage/curative intent patients.

Feedback received from doctors on the brochure wording and/or phrasing, when thought to be appropriate by the authors, was incorporated into the brochure. A haematologist indicated that it "May be worth noting that 'invasive' mindbody techniques (eg acupuncture) could be an issue in [a] setting of low platelets, and so forth" but did note the limitation for such details within the brochure's scope and intended broad message. Another clinician was concerned: "some fish oils have antiplatelet effect and could be an issue with haematology patients with low platelets." A fish oil caution was not included in the brochure because at risk patients are closely monitored, the antiplatelet effect is not great ( $10 \mathrm{~g}$ of fish oil per day has less effect on platelet function than $100 \mathrm{mg}$ of aspirin given intravenously [8]), and dietary fish oil may be consumed in amounts similar to standard supplements. One doctor sought the inclusion of B group vitamins and vitamin E for the treatment of peripheral neuropathy; however, a 2008 Cochrane review concluded insufficient evidence for the use of vitamin B [9], and vitamin E may have chemotherapy interaction complications [10]. Another prescriber's suggestion of adding grapefruit prohibition was not considered within the brochure brief.

Doctors were generally positive when optional extra feedback was given:

I think it is just right-short and balanced

Overall, great idea and good brochure

Good amount of writing. Messages are clear

Well put together brochure. Definitely useful

Excellent idea. I liked it. So many patients ask questions which this brochure is going to answer

Definitely a topic poorly understood by many patients and doctors/health care professionals. Patients often ask about the benefits/risks associated with CAMs during chemo. This brochure will help

One doctor criticized the brochure for being too academic: "Needs editing for English-it's written in academic English, needs to be properly edited for patient reading". However, the brochure was considered to be appropriate by the authors and so few changes were made; the brochure was instead submitted for publication and subsequent consumer testing to determine if it was understandable.

3.2. Patient Feedback. Patients were generally enthusiastic about the brochure and all 12 found the information clear and easy to understand. All patients thought that the information was relevant to them and that the brochure contained enough information to answer their CAM questions (Table 3).

It's a great little book- a good size that you would read because it is not over-involved. It's matterof-fact and gives you what you need to know in an easily understandable read. I think I would've found this booklet very beneficial when I started my regime

To all concerned with the research of the publication of this information-well done

I found it a great and informative book: clear and to the point, thank you 


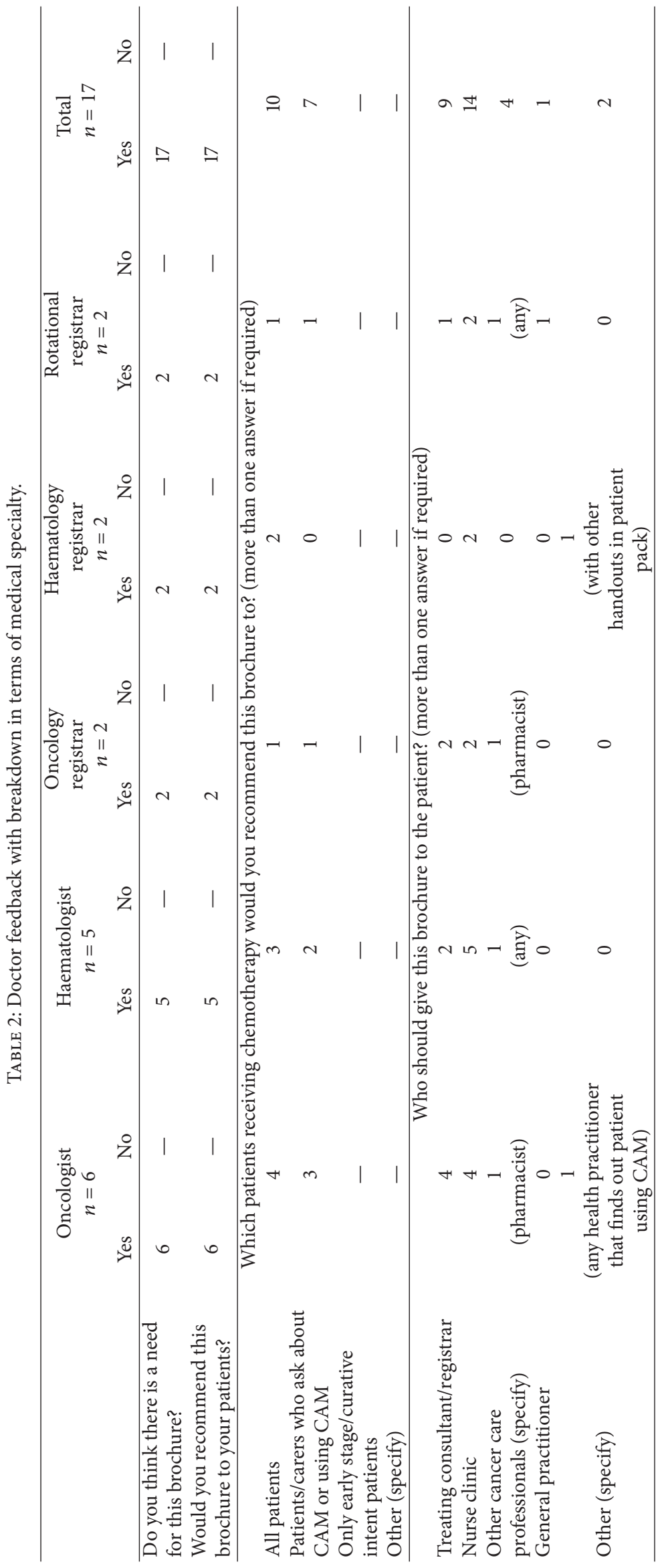


TABLE 3: Patient feedback, with breakdown in terms of gender and patient malignancy (Haem = haematology; Oncol = oncology) and numbers indicating those who answered yes $(\mathrm{Y})$, no $(\mathrm{N})$, or did not answer the question (na).

\begin{tabular}{|c|c|c|c|c|c|c|c|c|c|c|}
\hline & \multicolumn{2}{|c|}{$\begin{array}{l}\text { Total } \\
n=12\end{array}$} & \multicolumn{2}{|c|}{$\begin{array}{c}\text { Female } \\
n=7\end{array}$} & \multicolumn{2}{|c|}{$\begin{array}{l}\text { Male } \\
n=5\end{array}$} & \multicolumn{2}{|c|}{$\begin{array}{l}\text { Haem } \\
n=4\end{array}$} & \multicolumn{2}{|c|}{$\begin{array}{l}\text { Oncol } \\
n=8\end{array}$} \\
\hline & $\mathrm{Y}$ & N/na & $\mathrm{Y}$ & N/na & $\mathrm{Y}$ & N/na & $\mathrm{Y}$ & N/na & $\mathrm{Y}$ & N/na \\
\hline $\begin{array}{l}\text { Did you find the information clear, } \\
\text { easy to read and understand? }\end{array}$ & 12 & $0 / 0$ & 7 & $0 / 0$ & 5 & 0 & 4 & $0 / 0$ & 8 & $0 / 0$ \\
\hline $\begin{array}{l}\text { Was there enough information to } \\
\text { answer your questions? }\end{array}$ & 12 & $0 / 0$ & 7 & $0 / 0$ & 5 & 0 & 4 & $0 / 0$ & 8 & $0 / 0$ \\
\hline $\begin{array}{l}\text { Did the information explain medical } \\
\text { terms well? }\end{array}$ & 12 & $0 / 0$ & 7 & $0 / 0$ & 5 & 0 & 4 & $0 / 0$ & 8 & $0 / 0$ \\
\hline $\begin{array}{l}\text { Do you believe this information is } \\
\text { relevant to you? }\end{array}$ & 12 & $0 / 0$ & 7 & $0 / 0$ & 5 & 0 & 4 & $0 / 0$ & 8 & $0 / 0$ \\
\hline $\begin{array}{l}\text { Is the content culturally sensitive and } \\
\text { appropriate? }\end{array}$ & 10 & $0 / 2$ & 5 & $0 / 2$ & 5 & 0 & 3 & $0 / 1$ & 7 & $0 / 1$ \\
\hline $\begin{array}{l}\text { Is the design appropriate and } \\
\text { appealing? }\end{array}$ & 12 & $0 / 0$ & 7 & $0 / 0$ & 5 & 0 & 4 & $0 / 0$ & 8 & $0 / 0$ \\
\hline $\begin{array}{l}\text { Is the design clear, uncluttered, and } \\
\text { easy to follow? }\end{array}$ & 12 & $0 / 0$ & 7 & $0 / 0$ & 5 & 0 & 4 & $0 / 0$ & 8 & $0 / 0$ \\
\hline Is the print large and clear enough? & 12 & $0 / 0$ & 7 & $0 / 0$ & 5 & 0 & 4 & $0 / 0$ & 8 & $0 / 0$ \\
\hline $\begin{array}{l}\text { Did the photos and illustrations help } \\
\text { you to understand the information? }\end{array}$ & 11 & $0 / 0$ & 6 & $1 / 0$ & 5 & 0 & 3 & $1 / 0$ & 8 & $0 / 0$ \\
\hline
\end{tabular}

Additional patient feedback indicated that the main messages in the brochure, that is biologically active CAM may interact with chemotherapy and should be declared to conventional health professionals, were understood:

\section{I would certainly ask more questions of the nursing staff/GP/specialist}

Just check with your specialist first to make sure it's not going to have adverse reaction with the chemo

Talk to your doctor, ask questions about CAM, tell your doctor if you are taking any CAM

I was unaware that using "natural" remedies antioxidant, herbs could be counter productive

The brochure was also effective in making patients aware that CAM therapies are effective and safe to use for support during chemotherapy treatment:

\section{Complementary therapies can work}

Good to know about the yoga and other things which won't affect the chemo but could be substantially helpful with your wellbeing

Would certainly look into more of the massage, reflexology, and so forth, also the meditation and yoga

\section{Discussion}

The evidence-based educational brochure was designed to be brief and as neutral as possible, neither supportive of, or against CAM use. The authors deemed this necessary to not alienate potential CAM users who may be receiving alternative CAM advice [7]. Chemotherapy patients are likely to be contending with CAM advice from a variety of sources including family, friends, practitioners, and even casual acquaintances, who may be particularly insistent and persuasive when they regard themselves as having CAM expertise $[1,6,11,12]$. Conventional health practitioners need to provide evidence-based CAM information to chemotherapy patients to counter CAM misconceptions patients may have and to guide patients away from taking CAM which may be potentially detrimental to their treatment.

All cancer care doctors indicated they would use the brochure for their patients. A proportion of doctors wanted only patients asking about or using CAM to receive the brochure. These doctors were concerned that giving CAM information to patients may be misconstrued as being promotional of CAM use with chemotherapy and one patient did report she would look into more mind-body CAM and supplements that may help if she were able to take them, as a result of reading the brochure. If only patients who ask about CAM were offered the brochure, patients in need of CAM guidance with chemotherapy may be missed; cancer patients do not necessarily volunteer their CAM consumption unless asked [3], prefer their health care providers to initiate discussions regarding CAM use [13], want safety information regarding CAM with chemotherapy before they start treatment [6], and make CAM decisions at the same time as standard medical decisions [11].

Though there are existing general information resources on CAM use, chemotherapy patients want to receive specific evidence-based information on CAM use at the time of receiving chemotherapy [6]. This small population study demonstrated that a brochure showed promise in providing 
cancer patients' educational requirements on the safe use of CAM with chemotherapy and may be a useful tool for use by cancer care health professionals to educate patients on potential dangers of biologically active CAM use with chemotherapy and to provide patients with safe CAM alternatives if required.

\section{Conclusion}

The evidence-based CAM-chemotherapy patient brochure developed herein may be a useful adjunct for cancer care health professionals to educate patients on the potential dangers of biologically active CAM use with chemotherapy and to provide patients with safe CAM alternatives.

\section{Conflict of Interests}

The authors declare that there is no conflict of interests regarding the publication of this paper.

\section{Acknowledgment}

The authors wish to thank the Sunshine Coast Hospital and Health Service for publication design and printing assistance.

\section{References}

[1] B. Oh, P. Butow, B. Mullan et al., "The use and perceived benefits resulting from the use of complementary and alternative medicine by cancer patients in Australia," Asia-Pacific Journal of Clinical Oncology, vol. 6, no. 4, pp. 342-349, 2010.

[2] C. Zollman and A. Vickers, "ABC of complementary medicine. Complementary medicine and the patient," British Medical Journal, vol. 319, no. 7223, pp. 1486-1489, 1999.

[3] M. Tascilar, F. A. de Jong, J. Verweij, and R. H. J. Mathijssen, "Complementary and alternative medicine during cancer treatment: beyond innocence," Oncologist, vol. 11, no. 7, pp. 732-741, 2006.

[4] I. Meijerman, J. H. Beijnen, and J. H. M. Schellens, "Herb-drug interactions in oncology: focus on mechanisms of induction," Oncologist, vol. 11, no. 7, pp. 742-752, 2006.

[5] J. S. McCune, A. J. Hatfield, A. A. R. Blackburn, P. O. Leith, R. B. Livingston, and G. K. Ellis, "Potential of chemotherapy-herb interactions in adult cancer patients," Supportive Care in Cancer, vol. 12, no. 6, pp. 454-462, 2004.

[6] P. J. Smith, A. Clavarino, J. Long, and K. J. Steadman, "CAM use by patients receiving curative intent chemotherapy," European Journal of Oncology Pharmacy, vol. 8, no. s2, p. s42, 2014.

[7] P. J. Smith, A. Clavarino, J. Long, and K. J. Steadman, "Why do some cancer patients receiving chemotherapy choose to take complementary and alternative medicines and what are the risks?" Asia-Pacific Journal of Clinical Oncology, vol. 10, no. 1, pp. 1-10, 2014.

[8] N. Svaneborg, S. D. Kristensen, L. M. Hansen, I. Büllow, S. E. Husted, and E. B. Schmidt, "The acute and short-time effect of supplementation with the combination of n-3 fatty acids and acetylsalicylic acid on platelet function and plasma lipids," Thrombosis Research, vol. 105, no. 4, pp. 311-316, 2002.
[9] C. D. Ang, M. J. M. Alviar, A. L. Dans et al., "Vitamin B for treating peripheral neuropathy," Cochrane Database of Systematic Reviews, no. 3, Article ID CD004573, 2008.

[10] E. Ladas and K. M. Kelly, “The antioxidant debate," Explore, vol. 6, no. 2, pp. 75-85, 2010.

[11] L. G. Balneaves, L. Weeks, and D. Seely, "Patient decisionmaking about complementary and alternative medicine in cancer management: context and process," Current Oncology, vol. 15, supplement 2, pp. s94-s100, 2008.

[12] J. Öhlén, L. G. Balneaves, J. L. Bottorff, and A. S. A. Brazier, "The influence of significant others in complementary and alternative medicine decisions by cancer patients," Social Science \& Medicine, vol. 63, no. 6, pp. 1625-1636, 2006.

[13] M. A. Richardson, T. Sanders, J. L. Palmer, A. Greisinger, and S. E. Singletary, "Complementary/alternative medicine use in a comprehensive cancer center and the implications for oncology," Journal of Clinical Oncology, vol. 18, no. 13, pp. 25052514, 2000. 


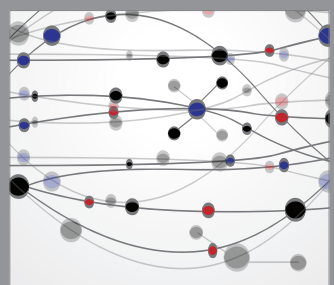

The Scientific World Journal
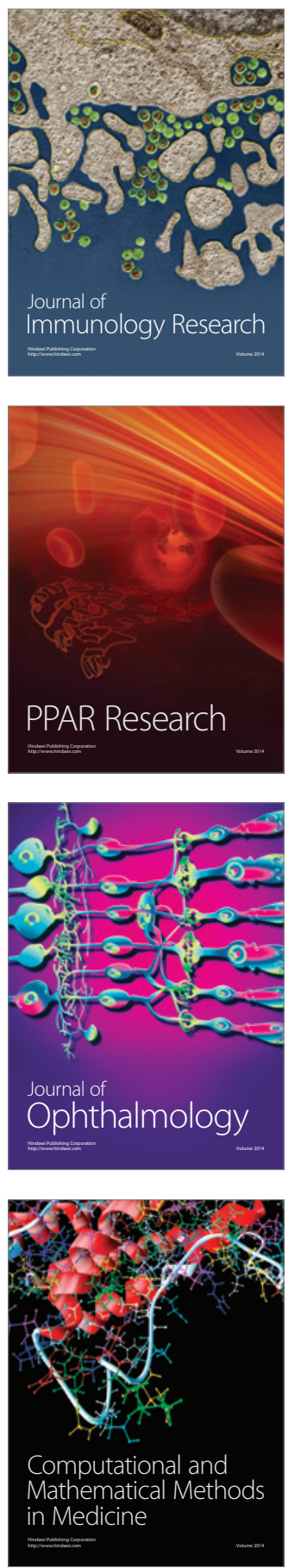

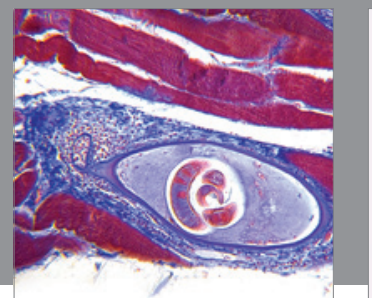

Gastroenterology

Research and Practice
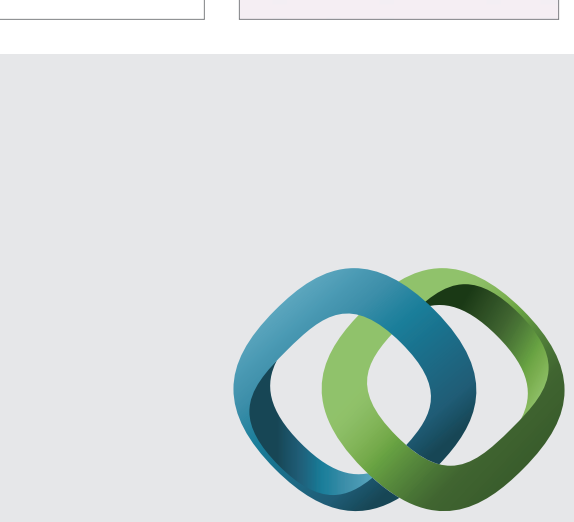

\section{Hindawi}

Submit your manuscripts at

http://www.hindawi.com
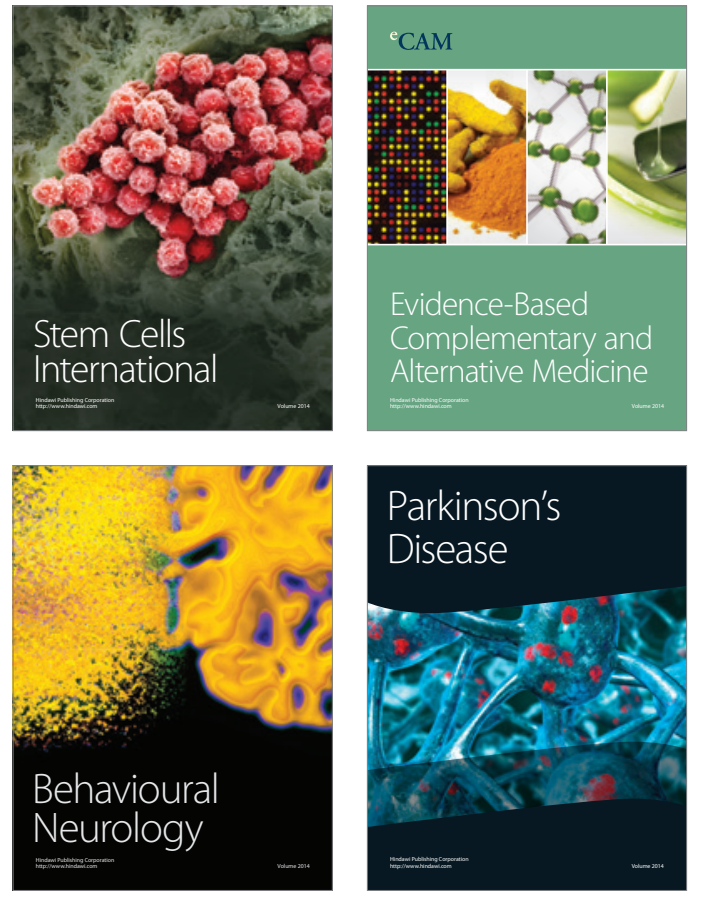
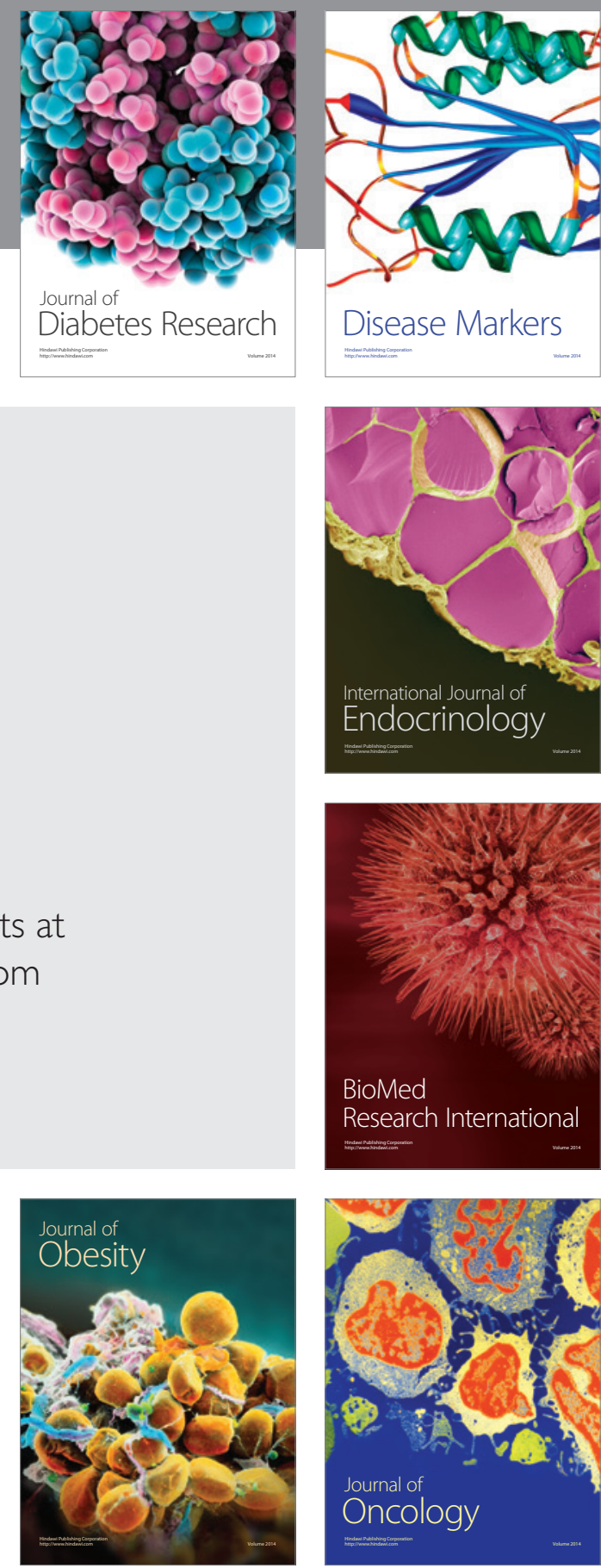

Disease Markers
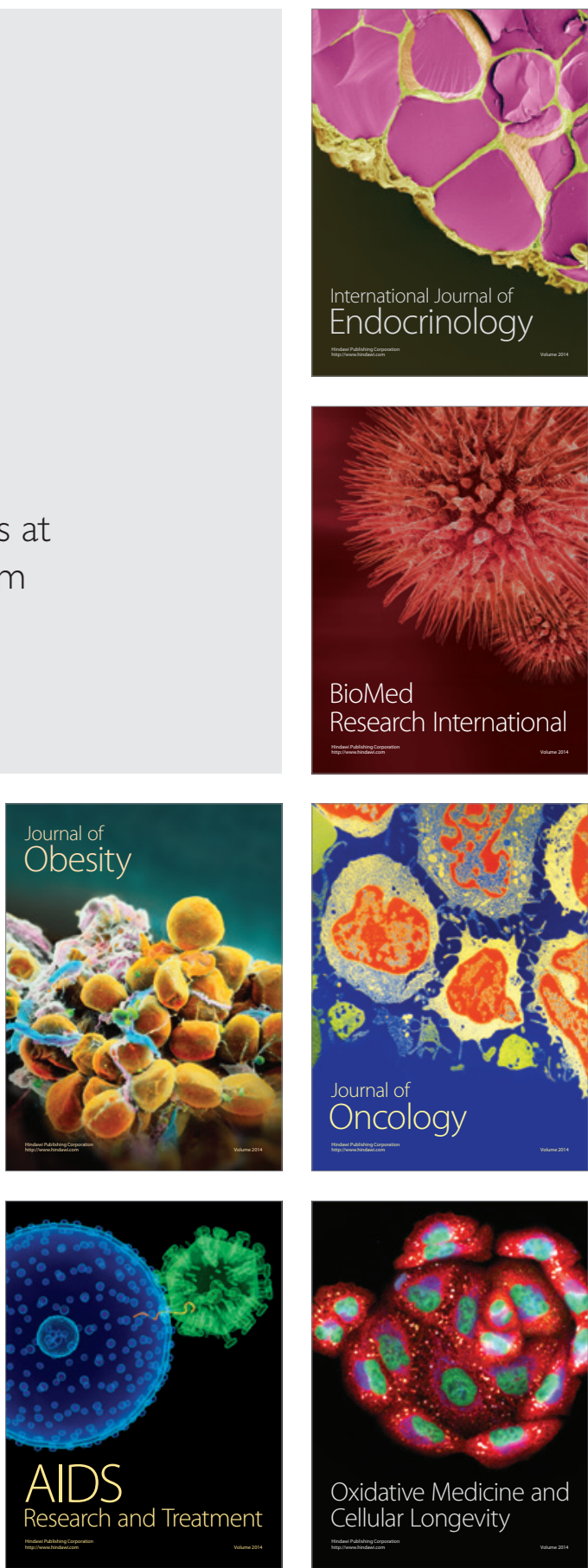